\title{
Davidsen-Nielsen, Niels: Tense and Mood in English. A Comparison with Danish. Mouton de Gruyter, Berlin / New York 1990. Topics in English Linguistics 1. x + 224 pp.
}

The grammatical categories of tense and mood are traditionally considered theoretically complex and, from the point of view of even the most advanced foreign language student, often difficult to use correctly. Professor Niels Davidsen-Nielsen from the Department of English at the Copenhagen Business School has let himself be challenged by the by no means easy task of analysing and describing the time and modality expressions which are realized grammatically in English and Danish and in his book he thus compares tense and mood in English with the corresponding categories in Danish.

The book is divided into eight chapters: 1. Introduction, 2. Auxiliaries, 3. Analysis of mood, 4. Analysis of tense, 5. Mood usage, 6. Tense usage, 7. Modal usage of tenses, and 8. Semi-auxiliaries and deontic modality. This division reflects the theoretical underpinnings of the analysis, and in the following we shall be concerned with these and only to a lesser extent with the analysis of specific examples.

It should be stated right away that the subcategorization of tense and mood, not least in a contrastive perspective, is like a multi-layered cake which it is almost impossible to cut in nice and even slices. Consequently, whichever way one decides to cut the cake, there will always be some irregular pieces left. Unavoidably, this is also the case in this book, but that does not change the fact that it is a very valuable contribution to the description and contrastive analysis of tense and mood in the two languages involved. As far as English is concerned, tense and mood have been described quite extensively from a variety of different points of view, but that is not the case for Danish, and it has been a primary task for Davidsen-Nielsen to define a set of categories which can be said to be both theoretically adequate for the analysis of tense and mood and a suitable tertium comparationis in the contrastive analysis of English and Danish.

In his analysis Davidsen-Nielsen includes not only the verb forms 
which express tense and mood by means of inflection, but also those that do so by means of grammatical verbs, that is, auxiliaries. As a consequence of this, it is the definition of the category auxiliary which decides exactly how much is comprised under the labels tense and mood respectively.

In order to delimit the class of auxiliaries from other classes of verbs, it is of course necessary to have a set of criteria or tests which are equally valid for both languages in the contrastive analysis; traditional syntactic criteria which are by definition language specific are therefore not applicable. In other words, what is needed is a set of criteria "which permit the analyst to single out a class of grammatical verbs which are intimately connected with another verb and which are similar to verbal inflections. It is not considered sufficient to propose a number of operational tests; the criteria should also isolate a class of verbs which is useful for the formulation of grammatical rules" (p. 22). For the purpose of this, Davidsen-Nielsen chooses four tests originally proposed by SpangHanssen (1983) for the definition of an auxiliary: 1. The meaning of an auxiliary is general and abstract. Apart from semantically empty words - like English do - its content is analysable in terms of temporal, aspectual, modal and diathetic values. 2. An auxiliary is functionally dependent in the sense that is it impossible to modify it without simultaneously modifying the lexical verb it combines with. In other words, Aux $+\mathrm{V}$ can only be modified globally. 3. The addition of an auxiliary does not affect the lexical restrictions of the verb it combines with. 4. An auxiliary is attached to a lexical verb without any intervening infinitive marker, i.e. it governs a bare infinitive or a participle (ibid.). These four test have the advantage of being equally applicable to English and Danish; it should be noted, however, that nothing is said about their universal validity.

In chapter 2 of the book the tests are discussed and applied to the verbs of the the two languages. Not surprisingly, it turns out that they do not establish a water-tight distinction between auxiliaries and full verbs, and as it is often the case in the analysis of natural language, the concept of imprecise categories (cf. e.g. Dahl 1985) offers a solution to the problem by claiming that not all members of a given set need have all relevant features in order to be included in the set. Therefore verbs which are auxiliaries according to some but not necessarily all the above tests are still considered auxiliaries in the analysis. Even though one might discuss these tests in their own right, we will not do so here but concentrate on 
the consequences they have for the analysis of tense and mood in the book.

As a result of these four tests, Davidsen-Nielsen operates with the following auxiliaries: In English the primary auxiliaries have (perfect tense), be (progressive aspect, passive voice), do (empty), will (future tense), and the modal auxiliaries may, might, can, could (epistemic possibility), must, need, should (epistemic necessity); in Danish the primary auxiliaries have (perfect tense), vare (perfect tense, passive voice), blive (passive voice), ville (future tense), and the modal auxiliaries kunne (epistemic possibility), måtte, behøve (epistemic necessity), skulle (epistemic report and necessity), burde (epistemic probability). This has some significant implications for the analysis of tense as well as that of mood. In the following we shall deal with the two categories in turn.

As far as tense is concerned, Davidsen-Nielsen uses this term in a relatively broad sense to refer to "any type of grammatically expressed location in time in the verb" (p. 54). Tense may thus also be said to be a deictic category. As appears from the above, he proposes a rather controversial tense system in that he operates not only with the dichotomy present vs past tense, but also includes future and perfect tenses and combinations of these with the result that he considers eight tenses in English as well as Danish: present, present perfect, past, past perfect, future, future perfect, future of the past, and future perfect of the past. In order to keep the eight tenses apart he defines a set of three semantic features which are not language specific. This is based primarily on Reichenbach (1947), Comrie (1985), and Vikner (1985), and in different combinations these features characterize the eight tense forms. They are [+/- PREVIOUS], [+/- POSTERIOR], and [+/- THEN]. [+/- PREVIOUS] "serves the function of keeping the four perfect tenses apart from the four nonperfect ones. The defining characteristic of the perfect tenses is that their event time precedes their reference time" (p. 62); [+/- POSTERIOR] "serves the function of keeping the four future tenses apart from the four non-future ones. The defining characteristic of the future tenses is that their event time follows their speech time or - in the case of the future of the past — their basis time" (ibid.); and finally [+/- THEN] "serves the function of keeping the four past tenses apart from the four non-past ones. The defining characteristic of the past tenses is that their reference time or - in the case of the future of the past and future perfect of the past - their basis time precedes their speech time" (ibid.). The semantic characteristics of the eight tenses are summarized in table 1 below (copied 
166

from page 63 of the book):

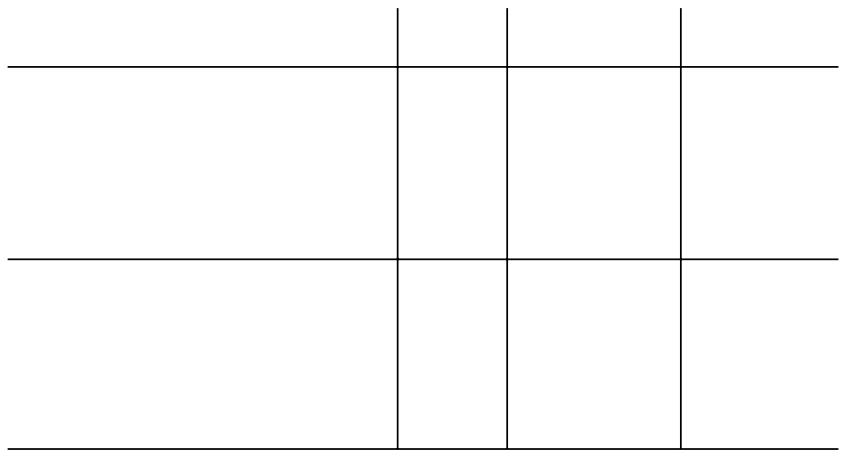




\section{Table 1}

Though, as it is also pointed out by Davidsen-Nielsen himself, the tense system proposed here is basically non-mainstream in the tradition of English linguistics, it appears quite attractive at first sight for the simple reason that any given verb phrase (i.e. grammatical form) has a prototypical meaning and is open to pragmatic interpretation in any given context.

Davidsen-Nielsen offers convincing arguments in favour of regarding the perfect expressed by have/have $+\mathrm{V}$ as being temporal rather than aspectual and of reserving the notion of aspect for the distinction in English between so-called progressive and non-progressive verb phrases. With reference to Comrie $(1976,3)$ he argues that aspect "serves the function of presenting the event described by the verb either with or without reference to its internal temporal constituency" (p.68) and "in both English and Danish, perfect vs. non-perfect constructions tell us nothing about internal event time, i.e. about the extension or temporariness of the verbal event. What they do tell us about is external event time, i.e. about the relative placing of an event described by a verb in a chronological order. Since the perfect forms are in this respect similar to the evident tenses (...), the category tense need not be unduly streched in order to accommodate them as tenses. It is only by the fact that their reference time does not coincide with their event time that they might be considered "deviant"" (p.68f). We shall leave out any in-depth discussion of the perfect construction here and instead be concerned with the socalled future tense.

When we look at the tense system per se without taking into consider- 
ation the modal verbs or other expressions of future time reference, it might appear to be quite reasonable to include also a future tense expressed by means of will (Danish vil) $+\mathrm{V}$ in the tense system. However, if the analysis also concerns expressions of future time reference by means of semi-auxiliaries or lexical verbs, or if we consider modality and the meaning of the modal verbs in general, the singling out of will/vil + $\mathrm{V}$ as future tense becomes more debatable.

In his discussion of the concept of modality, Davidsen-Nielsen makes a basic distinction between categorical (unmodalized, factual) utterances and modalized ones and, within the latter, a distinction between epistemic and non-epistemic modal utterances. Except for the specific instances where various tenses are used modally (cf. ch. 7 Modal usage of tenses), the eight tenses in themselves are prototypically non-modal. However, in the paragraph on future time reference, it becomes problematic to keep the basically non-modalized tenses and the modal expressions apart.

In 2.2 the basic syntactic differences between epistemic and non-epistemic modal verbs are described. Out of context, example (1) below is ambiguous and may be interpreted as both epistemic and non-epistemic:

(1) a. She may go home (tomorrow)

b. Hun kan rejse hjem (i morgen)

(2) a. She may have gone home

b. Hun kan være rejst hjem

(3) a. If she may go home (tomorrow), I'll accompany her

b. Hvis hun kan rejse hjem (i morgen), vil jeg følges med hende

However, in (2) where the modal verb occurs with a following perfect infinitive, the modality of may / kan can only be interpreted as being epistemic, whereas in (3), where the modal occurs in the subordinate clause of a conditional sentence, the modality can only be interpreted as being non-epistemic. Now, if instead of may and kan we insert will and vil, we get (4)-(6):
(4) a. She will go home (tomorrow)
b. Hun vil rejse hjem (i morgen)
(5) a. She will have gone home (tomorrow)
b. Hun vil være rejst hjem (i morgen)
(6) a. If she will go home tomorrow, I'll accompany her
b. Hvis hun vil rejse hjem i morgen, vil jeg følges med hende 
According to Davidsen-Nielsen's analysis, will / vil in (4) express nonmodal future tense, in (5) non-modal future perfect, and in (6) volition (i.e. modality). In (4) and (5) will / vil are thus auxiliaries, whereas they are lexical verbs in (6). His primary argument for this analysis is that utterances "with non-volitional will and ville differ from utterances with evident modals in being categorical. For example, Bill will finish his novel differs semantically from Bill may finish his novel in describing the actual future - not an alternative world in which the novel is finished" (p. 68). This analysis obviously depends on exactly how one defines the distinction between categorical and non-categorical expressions, and how one defines the philosophical concept of possible worlds in relation to natural language expressions. Still, within the concept of possible worlds, the same examples could be analysed as natural language expressions of different points on the semantic scale of epistemic modality ranging from impossibility to absolute certainty, cf. p. 44, where Davidsen-Nielsen himself says that "Between the poles of a negative categorical utterance and a positive categorical utterance there is a modal area ranging from what is considered remotely possible to what is believed but no[t] known to be necessary". In such an analysis, the may (Danish kan) of epistemic possibility is closest to the point of impossibility, whereas the will (Danish vil) of predictability in found somewhere in the middle, and the must (Danish $m a ̊$ ) of necessity is found closest to the absolute certainty or nonmodal categorical statement. By introducing a modal operator [PREDICTABILITY] $\left(\mathrm{t}_{0}<\mathrm{t}_{1}(\right.$ nec $\left.p)\right)$ between the modal operators [POSSIBILITY] (pos $p$ ) and [NECESSITY] (nec $p$ ) (cf. Lauridsen 1988), we are able to accommodate the modal verbs which have a strong element of futurity among their prototypical features in the description of modality and modal verbs in general. This alternative analysis makes it possible to account — also in a contrastive analysis of English and Danish — for the expressions of future time reference which are, in Leech's words, "tinged with modality" $(1987,57)$ and to keep them apart from the non-modalized ones.

Apart from the simple present, the present progressive, or lexical verbs like be going (to) or be about (to), which may all be said to be nonmodalized future time expressions, and also apart from the will (Danish vil) of future prediction dealt with above, future time may be expressed by the present tense of be to or (other) modal verbs.

(7) a There is to be a new hearing

b. Der skal være en ny høring 
(8) a. I am to interview her today

b. Jeg skal interviewe hende i dag

Davidsen-Nielsen offers (7a) and (8a) as examples of "future arrangement outside the control of the speaker or the subject noun phrase referent" (p.119). We will claim here, that just as the example You are not to smoke (ibid.), (7) and (8) express deontic modality (cf. Lauridsen 1988, 146ff). That we have got deontic rather than epistemic modality in (7) and (8) is seen most clearly in the Danish examples, where the fact that skal may appear in a non-tensed form (Der har skullet vare en ny høring (men den blev udsat) and Jeg har (engang) skullet interviewe hende (men det blev ikke til noget)) or in the subordinate clause of a conditional sentence (Hvis der skal vare en ny horing (vil han blive fort som vidne) and Hvis jeg skal interviewe hende $i$ dag (skal det vare klokken 3)) indicates that the modal verb is non-epistemic. Furthermore, a semantic paraphrase like At a time $t_{1}$ posterior to $t_{0}$ it is necessary for me to $p$ (where $p=$ "I interview her today") also indicates the deontic interpretation.

The proposition following an epistemic modal may refer to an event in the past, the present or the future, whereas the proposition following a deontic (non-epistemic) modal refers to an event in the (extended) present or the future. Thus it is not only in examples like the above with will / vil or be to / skal that there is a feature of modality as well as one of futurity in the prototypical semantic properties of the modals; this is also the case with other epistemic as well as deontic modals (given the appropriate context), cf. e.g. Davidsen-Nielsen's examples p. 119f or the epistemic should/skulle which occur with future time meaning in their past tense forms in the subordinate clause of conditional sentences like Should you happen to be passing, do drop in (p. 88).

If one chooses the tense system with eight tenses as one's point of departure and thus operates with a set of future tenses, one must be ready, somewhere else in the description, to account for the other grammatical or lexical (modal or non-modal) expressions which may have future time reference and which may therefore be said to have the property of futurity as one of their dominant semantic features; DavidsenNielsen does that in 6.2, that is, in the chapter on tense usage even though the future time reference expressions comprise more that just the grammaticalized expressions of time as they were defined in the first chapters of the book. 
If, on the other hand, one chooses the concept of modality and the meaning of the modal verbs as one's point of departure, one must recognize that some of these modal expressions have a very marked property of future time reference. This may be accounted for by means of the concept of imprecise semantic categories; because in such a category the dominant feature may vary according to the context so that, for instance, either the modal or the temporal feature is the dominating one (cf. the discussion of imprecise categories in Dahl 1985 and Lauridsen 1988).

It is a characteristic of Davidsen-Nielsen's extended tense system as well as the modal system sketched above that they both consist of a set of semantic categories which may function as the tertium comparationis of a contrastive analysis and that they have typical grammatical or lexical expressions in both languages. So what the above discussion boils down to is, at least to a certain extent, a question of how to cut one and the same multi-layered cake.

When we come to the analysis of mood, the picture is different. Mood is defined as grammaticalized expressions of modality and, as indicated above, modality is defined within the concept of possible worlds, cf. e.g. Perkins 1983. In the analysis adopted in the book, there is a basic distinction between morphologically expressed mood, which is termed synthetic mood, and syntactically expressed mood, which is termed analytic mood (cf. Huddleston 1984, 164ff). Synthetic mood comprises the subcategories of subjunctive and imperative, whereas analytic mood comprises possibility and necessity in English and possibility, necessity, probability, and report in Danish. As pointed out by Davidsen-Nielsen (p. 7f) these categories, in contrast to those of time and tense, do not form an organic system. The categories of mood, subjunctive, and imperative are form categories, whereas possibility, necessity, probability, and report are semantic categories.

From a theoretical point of view, it is problematic to operate with a system that consists of a mixture of form and meaning categories. It would be much more satisfactory if it was possible to define a semantic system which is not language specific and which can therefore function as the tertium comparationis in a contrastive analysis; the system would then have a set of grammatical and lexical expressions in the individual languages. Such a semantic system is actually available for the analysis of mood in the semantic concepts of possible worlds and modality. However, whereas it was possible to define tense as - prototypically grammaticalized location in time and then end up with an organic system 
of on the one hand semantic categories and on the other form categories, this is not quite as simple in the case of mood because modality is expressed in so many different ways: by means of inflection, modal auxiliaries, semi-auxiliaries and lexical verbs, by means of tense, and by means of lexical expression within all the major parts of speech.

Furthermore, as a consequence of the definition of grammaticalized expressions as comprising verbal inflection and primary auxiliaries, and a consequence of the definition of auxiliaries presented in chapter 2, an analysis of the epistemic modal verbs is included whereas the non-epistemic ones are left out of the analysis of mood. This means that one and the same modal verb (or two homographic modals) are not considered together even though they basically express the meaning of the same modal operator. As already mentioned, the above example (1) with may/ kan is ambiguous; if it has the meaning of epistemic possibility as in (2), it is included in the analysis of mood, but if it has the meaning of deontic possibility or permission as in (3), it is referred to the additional chapter 8 on semi-auxiliaries and deontic modality.

In addition to this, it does not seem to be a felicitous solution that, in the analysis of mood, the synthetic forms are described as having both epistemic and non-epistemic meaning, whereas the analytic forms (the modals) are described as having only an epistemic meaning because the analysis of the non-epistemic meanings are regarded as belonging outside the scope of the mood system. This is all the more so because both epistemic and deontic expressions are allowed also in the analysis of future time reference.

Finally, it seems unsatisfactory that the subcategory of analytic mood has two members in English, but four in Danish; the semantic categories of probability and report may obviously also be expressed in English, but the trouble is again that it is not necessarily done by means of an auxiliary. As far as probability is concerned, Davidsen-Nielsen assumes that it is expressed by the auxiliary should, which is otherwise the typical expression of weak necessity in English, or by the lexical verb ought to (cp. p. 92); the semantic category of report takes the form of lexical expressions like e.g. be said to.

When all this is said, it should be stressed, however, that the main objective of the book is to describe the categories of tense and mood rather than those of time and modality; the inconsistencies in the analysis of mood indicated above stem from the fact that the grammatical category of mood expresses a relatively well-defined part of the semantic cate- 
gory of modality, that is, epistemic modality plus, in the case of imperative and subjunctive (cp. 5.5 and 5.6), certain elements of deontic modality. However, the highly frequent modals are not analysed in their deontic or dynamic senses in the analysis of mood, and the close semantic relations between modals of the same lexical stem - whether they are considered auxiliaries, semi-auxiliaries or lexical verbs - are therefore not clearly captured in the book. Out of context an example like He can't sleep at their house may be interpreted as epistemic possibility ("It is not possible that he sleeps at their house"), as deontic possibility ("He is not allowed to sleep at their house") or, finally, as dynamic possibility ("He is unable to sleep at their house"). The often subtle semantic differences between the subcategories obviously often lead to indeterminacy so that an example may be ambiguous even in context, and such examples are very difficult to explain if one does not have a clear picture of the relations between the different meanings of the same modal.

In the first four chapters (roughly one third of the book) DavidsenNielsen accounts for the analyses proposed. These are then carried out in the last four chapters (two thirds) of the book.

Chapter 5 deals with mood usage. Within each of the semantically defined subcategories (possibility, necessity, probability and report), the meaning of the present and past tense forms of the modals in English and Danish are discussed and contrasted. This also goes for the modals in interrogative clauses (especially where the choice of modal differs from that of declarative clauses) and for the modals in negated clauses. In the latter case, Davidsen-Nielsen points out the important difference between the negation of the modality and the negation of the following proposition, especially where this leads to the choice of two different modals, cf. an example like He must be tired after such a journey, the negation of which will be either He needn't be tired after such a journey or He can't be tired after such a journey. As a negation of must, needn't negates the modality, whereas can't negates the following proposition.

In 5.5-5.6 the semantics of the grammatical forms imperative and subjunctive are then analysed and contrasted, and in 5.7 the occurrence of the Danish modal auxiliaries in their infinitive form is briefly touched upon.

With each individual of the eight time and tense categories as his point of departure, Davidsen-Nielsen discusses and contrasts the tense systems of the two languages in chapter 6 . The findings of these analyses, with emphasis on the areas of difference between English and Danish, are 
then summarized in 6.9. In addition to this there is a special paragraph on tense usage in indirect speech (6.10) and on tense usage in non-finite clauses (6.11). Tenses in their modal usage is analysed and contrasted in chapter 7 with a summary in 7.9. Finally, deontic modality expressed by what Davidsen-Nielsen chooses to define as semi-auxiliaries (modals) is analysed in chapter 8 .

The analyses within the individual categories are thorough and are accompanied by many illustrative examples. Davidsen-Nielsen has chosen to use a mixture of authentic examples from corpora or literary sources as well as examples from other works on the subject, dictionaries, or even invented examples. Even though I would generally advocate the use of authentic examples, it must be admitted that out of context some of them appear a bit odd, cf. She said that she would be able to distinguish it from its fellows (p. 152). The verb phrase would be serves the function of illustrating the non-conditional use of the future of the past; but taken as a whole the example seems somewhat strange, perhaps because of the anaphoric it and its without an antecedent. However, this is a minor detail and does not shatter the general impression of the example material.

Throughout the book the Danish examples are glossed in English so that it is also accessible to readers who are not well-versed in Danish. This is a great advantage not only for native speakers of English who want to know more about Danish in comparison with their own language, but also for linguists or other people without any knowledge of Danish, but with a general interest in the fields of tense and mood.

The analysis of the two languages is in principle parallel, but in the contrastive analysis, and especially in the paragraphs that summarize the usage within a specific (set of) categories, Davidsen-Nielsen has deliberately chosen a Danish to English orientation so that he focusses on contrasts from the point of view of the Danish learner of English. The analyses in the book therefore offer a particularly solid basis for the development of contrastively orientated teaching material for Danish students of English at an advanced level.

Even though the book "makes use of very little formalism and explains many grammatical terms" (p. 14), only advanced students of English, Danish, or linguistics will benefit from reading it on their own. Professional linguists with an interest in the complicated matters of time, tense, modality, and mood, or with a general interest in contrastive linguistics will find lots of thought-provoking inspiration in the discussions and 